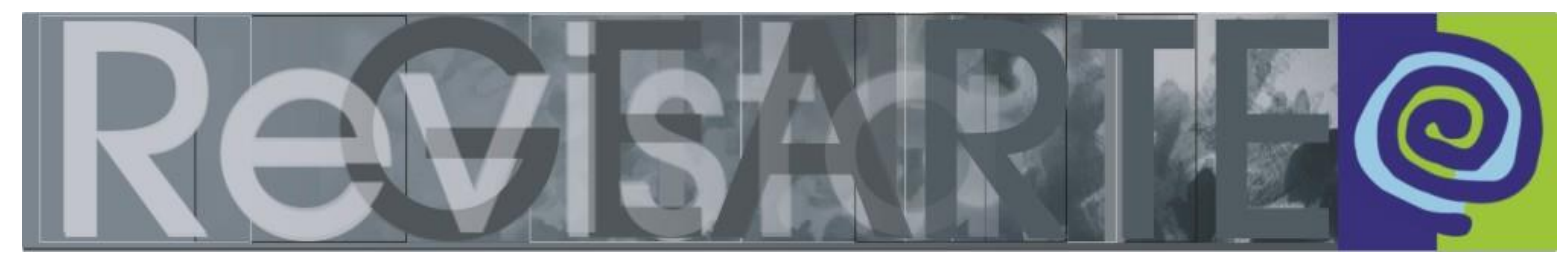

\title{
O "pulo do gato" e a mediação em arte: possibilidades de interação
}

\author{
Marília Forgearini Nunes (GEARTE/UFRGS - Brasil)
}

\begin{abstract}
RESUMO
O ser humano tem nas diferentes manifestações da linguagem uma maneira de compreender a si mesmo e o mundo que habita. As manifestações que envolvem a arte, especificamente as das artes visuais, necessitam para sua compreensão da capacidade de ver. No entanto, ver pode ser uma ação desatenta e que pouco auxilia na produção de sentido. O presente artigo destaca a importância do olhar atento para que se compreenda melhor a arte imagética. Esse olhar precisa ser mediado para que ultrapasse a desatenção que nada diz daquilo que vê e alcance a atenção produtora de sentido. Com base na narrativa do livro de imagem Pula, gato! (CASTANHA, 2008a), discutiremos a experiência com as artes visuais e explicitaremos regimes de interação (GREIMAS, 2002; LANDOWSKI, 2009;2010) que podem perpassar a experiência mediada na interação com objetos artísticos.
\end{abstract}

\section{PALAVRAS-CHAVE}

Mediação; regimes de interação; educação; arte.

\section{ABSTRACT}

The humans have on different manifestations of language a way to understand themselves and the world they inhabit. The manifestations that involve art, specifically the visual arts, need the ability to see to be comprehended. However, seeing can be an inattentive action that does not help in the process of meaning production. This paper highlights the importance of an attentive look that overcomes the inattentiveness that nothing says about what is seen and reaches the attention to produce meaning. Based on a narrative from an image book, Pula, gato! (CASTANHA, 2008a), we discuss the experience with visual art and explain the regimes of interaction (GREIMAS, 2002; LANDOWSKI, 2009; 2010) that may pervade the mediated experience in the relation with objects of art.

\section{KEYWORDS}

Mediation; regimes of interaction; education; art.

[...] para suportar tudo isso e tornar-se melhor pela sua própria sabedoria, o homem inventou uma ferramenta, a linguagem. [...] Dentre elas uma linguagem se fez especial, a linguagem da arte. Feita para o homem mergulhar dentro de si mesmo trazendo para fora e para dentro dos outros homens as emoções do próprio homem.

(MARTINS; PICOSQUE; GUERRA, 2010, p. 5)

Somos seres dotados de uma ferramenta essencial para compreender o mundo que habitamos: a linguagem. Precisamos dela nas suas mais diferentes formas para melhor entender e viver nesse mundo que nos acolhe. Apesar de serem um invento humano, as diversas linguagens não são sentidas ou compreendidas de maneira igual nem inerente ao ser. As experiências de cada um interferem na produção de sentido decorrente do interagir com cada produto das diferentes linguagens (artística, musical, 
literária,...). Experimentar, interagir, vivenciar são ações humanas que possibilitam melhor interpretar o mundo e produzir sentidos a partir das linguagens que 0 constituem.

Temos então um contraponto, ao mesmo tempo que as diferentes linguagens, com destaque aqui para a arte, permitem-nos compreender melhor o mundo que habitamos, principalmente, nossas emoções e modos de sentir, essa compreensão não é inata. Há a necessidade de experimentar a arte para que se possa compreendêla.

Podemos passar pelo largo da vida sem alcançar essa compreensão, considerando, pela falta de contato com os diferentes produtos da linguagem artística, ou por uma simplificação demasiada do sentir, que a arte inexiste ou pouco interfere no que somos e no modo como habitamos esse mundo. Tomamos, por exemplo, a imagem, um objeto de expressão da linguagem artística que exige de nós primordialmente a capacidade física da visão. Podemos concluir que se vemos, somos capazes de interagir com a imagem. A questão, no entanto, não está apenas na capacidade de ver, mas no modo como usamos essa capacidade: vemos, sem atenção, involuntariamente, somente exercendo nossa capacidade física da visão, ou olhamos, com atenção e entrega emocional e cognitiva?

Nesse texto, pretendemos discutir a necessidade de promover experiências nas quais a capacidade natural de ver seja instigada a ser vivenciada como olhar, atento, sensível e produtor de sentido, num movimento emocional e cognitivo que permite ao sujeito ampliar a compreensão do seu mundo e das suas emoções. Para isso, tomaremos uma obra literária infantil cuja linguagem de expressão é a imagem. A leitura de Pula, gato!, obra de Marilda Castanha (2008a), auxiliará a refletir sobre como interagimos com as artes visuais, e a necessidade de que essa interação seja pensada como vivência mediada de modo a instigar o olhar que não somente vê, mas produz sentido a partir do que olha.

A análise da obra, baseada na semiótica discursiva (BARROS, 2005), procurará identificar a oposição semântica que estabelece o seu conteúdo discursivo relacionando-a com as qualidades sensíveis das imagens. Esse será o caminho para pensarmos a experiência com a arte. A oposição semântica identificada na narrativa 
presente no livro de imagem em questão auxiliará a delimitar alguns princípios mediadores, pensando nas práticas educativas, tanto em nível formal quanto não formal que pretendam instigar o olhar e a compreensão do mundo a partir da arte.

\section{Pula, gato! : metáfora das interação com objetos artísticos visuais}

Pula, gato!' (figura 1), de Marilda Castanha (2008a) (figura 1), conta, por meio de imagens, a história de uma menina que passeia por uma galeria de Arte, onde estão expostas obras de artistas brasileiros consagrados. Ao longo dessa visita, um gato, que interage com a menina, chama-nos atenção por ser algo inusitado nesse local onde, normalmente, não é permitida a presença de animais. O gato, no entanto, faz parte de um dos quadros expostos na galeria. Esse quadro captura a atenção da menina que, distraidamente, caminhava pelos corredores do espaço de exposição.

Figura 1 - Capa da obra Pula, gato!

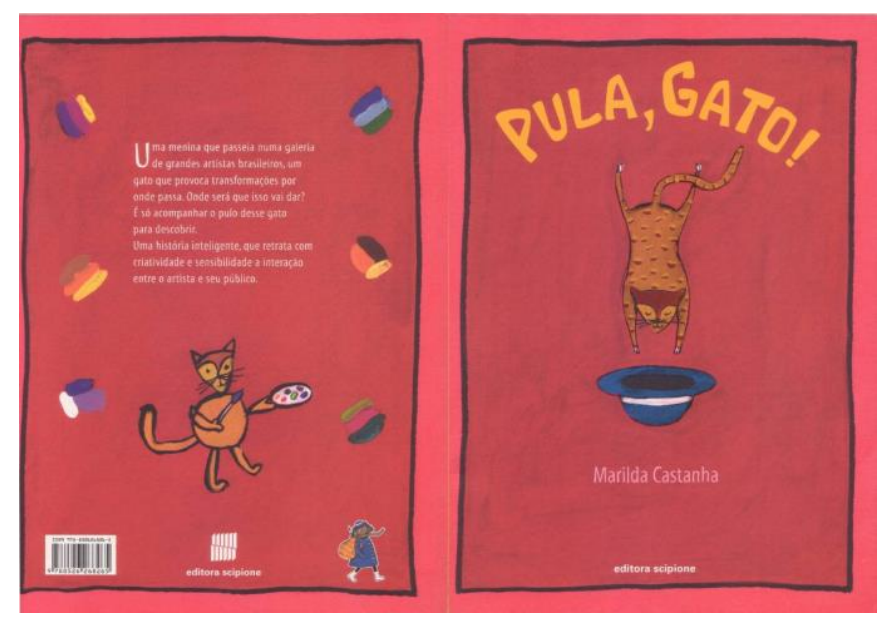

Fonte: CASTANHA, 2008a

O encontro do olhar da menina com esse quadro ou com o próprio gato nele apresentado é o que deflagra a ação narrativa. A partir de então, o gato passa a observar a menina e seu distraído passeio pela galeria, persegue-a e salta sobre ela. O pulo do gato surpreende a menina e a leva ao encontro com uma nova obra, dessa vez uma pintura feita pelo próprio gato, que de personagem de uma obra assume o papel de artista, pintando a si mesmo com traçado infantil junto com a menina. Todas essas ações são acompanhadas de perto pelas obras expostas na galeria de arte que

\footnotetext{
${ }^{1}$ Essa análise é parte da pesquisa de tese defendida em dezembro de 2013 junto ao Programa de Pósgraduação em Educação PPGEDU/UFRGS, com financiamento do CNPq.
} 
não compõem apenas o espaço narrativo, mas também tornam-se atores ao reagirem diante dos atos que presenciam junto com o leitor.

De acordo com a autora da obra, as imagens que compõem a narrativa oferecem ao leitor uma perspectiva cinematográfica de todas as ações. Marilda Castanha (2008b) diz que ao produzir as imagens imaginou-se com uma câmera na mão, oferecendo ao leitor o movimento de se afastar e se aproximar da cena, de acordo com o que quiser destacar. Além de permitir uma perspectiva diferenciada das cenas, entendemos que esse modo de apresentação também oferece ao leitor 0 acesso a uma configuração já conhecida, a partir das produções da mídia televisiva presentes no cotidiano das crianças. Segundo Cademartori (2012, p.3),

\footnotetext{
assistindo aos desenhos animados, crianças se familiarizam com as diferentes convenções representativas dos estilos visuais. Além disso, desenhos animados incorporam, além do simples uso de colagens e fotos, efeitos especiais importados do cinema e recursos de programas de computador.
}

O gato e a menina são os fios condutores da história narrada. É a partir das suas ações e interações que podemos identificar efeitos de sentido que nos auxiliam a traçar o percurso gerativo de sentido desse texto imagético. A presença desses dois atores, no contexto de uma galeria de arte, é a ideia deflagradora das possibilidades significativas desse texto. Tomaremos esses efeitos de sentido, delimitados por uma oposição semântica para discutir duas maneiras de interagir com o objeto artístico e destacar a importância da mediação para que o olhar mais atento e produtor de sentido seja instigado quando em interação com a arte.

Um espaço museológico tradicional, onde encontramos expostas obras de arte, pressupõe um comportamento determinado das pessoas que por ele circulam com a intenção de visitá-lo. Quadros pendurados em boa parte das paredes, esculturas e instalações dispostas em locais específicos permitem aos visitantes a sua apreciação. Nessa organização do espaço, está implícito um comportamento: um olhar atento, que busca produzir sentidos a partir do que vê e sente, durante a visita. O caminhar pelas salas e/ou corredores dessa galeria é guiado por esse olhar, sua velocidade, bem como o tempo transcorrido nessa ação, vinculam-se diretamente ao modo como que interagimos com as obras expostas. 
Esse modo previsível de comportamento pode até mesmo ser motivo de ironia como podemos perceber na charge ${ }^{2}$ (Figura 2), cuja legenda ${ }^{3}$ apresenta uma instrução bastante descritiva de como o visitante deve se comportar em uma galeria de arte. Mesmo irônicas, as ações descritas demonstram um comportamento esperado, o de que o visitante volte a sua atenção ao que está exposto na galeria, que mantenha certa distância das obras, não sendo permitido tocá-las.

Figura 2 - Charge sobre o comportamento das pessoas em uma galeria de Arte.

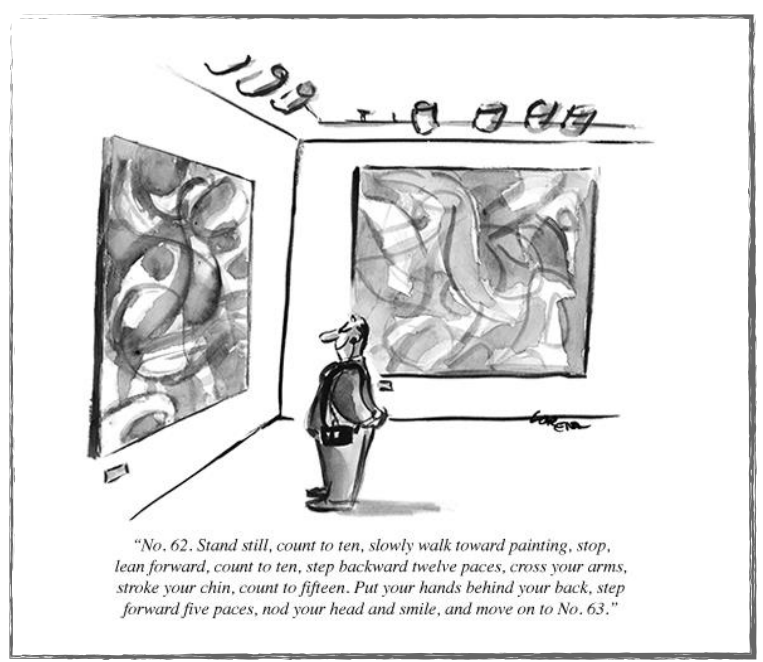

Fonte: http://demoura.tumblr.com/post/ 15851581321/instrucoes-para-comportamentonuma-galeria-de

O mesmo tom de ironia é reforçado na obra de David Prudhome, La traversée du Louvre (2012) (Figura 3), na qual o autor retrata a relação que os visitantes estabelecem com algumas das 36.000 obras que existem no Museu do Louvre, em Paris. Prudhome, ao longo das quase 80 páginas do livro a partir de "um olhar sensível e divertido [...] [retrata] os visitantes [...] e [o] relacionamento "estranho" que "eles têm com as obras" 4 .

2 A autoria da charge não foi identificada. Disponível em: http://demoura.tumblr.com/post/ 15851581321/instrucoes-para-comportamento-numa-galeria-de. Acesso em: 4 Mai. 2012.

3 "No62. Fique em pé, conte até dez, caminhe vagarosamente em direção à obra, pare, incline-se para frente, conte até dez, caminhe 12 passos para trás, cruze os braços, coce o queixo, conte até quinze. Coloque as mãos para trás, caminhe cinco passos para frente, balance a cabeça e sorria, e siga em frente ao No.63". (Tradução nossa).

4 Tradução livre e adaptada de: "David Prudhomme jette un regard sensible, amusé et tendre sur les visiteurs qu'il croise et les "étranges" relations qu'ils entretiennent avec les œuvres". Disponível em: http://www.louvre.fr/expositions/la-traversee-du-louvre-de-david-prudhomme. Acesso em: 02 Mai, 2013. 
Figura 3 - Capa da obra La traversée du Louvre

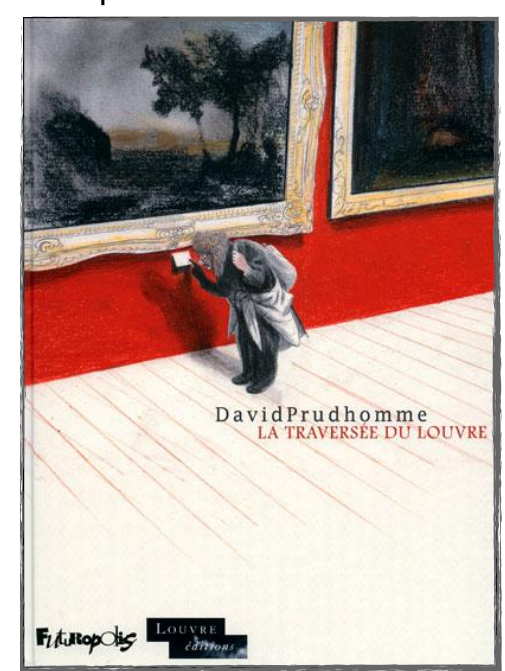

Fonte: PRUDHOMME, 2012

Na obra Pula, gato!, observamos que a menina está na galeria, caminha por seus corredores, mas não tem sua atenção voltada para as obras que lá estão expostas. Apenas uma obra atrai a atenção dela, o quadro que apresenta o gato (Figura 4). A menina encara-os (o quadro e/ou o próprio gato) de frente, sobe em uma banqueta para melhor visualizá-los e para ficar na mesma altura da obra e do gato nela apresentado. No entanto, não repara nas demais obras, passa por elas, mas não Ihes volta o seu olhar.

Figura 4 - Uma obra atrai a atenção da menina

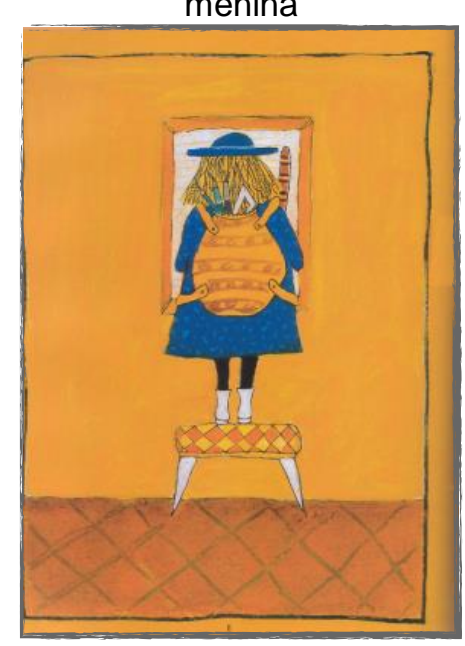

Fonte: CASTANHA, 2008, p. 9

A menina interage com o gato, encara-o de frente e isto o provoca a buscá-la. Como em uma animação, o gato salta do quadro e segue a menina pelos corredores 
da galeria (Figura 5). Seu olhar, atento, persegue a distraída menina que caminha em meio às obras de arte. Percebemos nessa sobreposição de ações um efeito de sentido que pode levar-nos a oposição semântica sobre a qual essa narrativa se constrói e que nos serve para refletir a respeito da interação com a arte: /atenção/ e /distração/.

Figura 5 - O gato pula do quadro

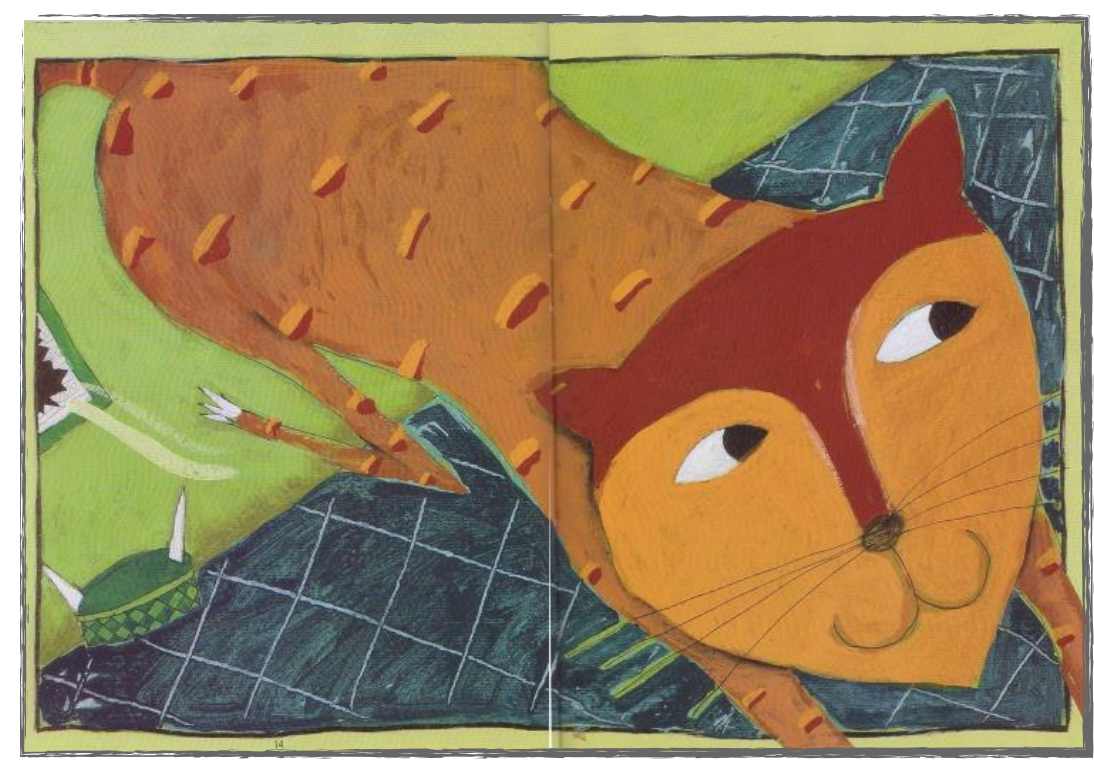

Fonte: CASTANHA, 2008, p.15-16

A atenção diz respeito ao gato, que busca a menina, e às pinturas, expostas na galeria, que percebem a interação entre a menina e o gato e acompanham a tudo atentamente. A distração está relacionada à menina, que após encarar o gato pintado na obra, nada mais percebe, nem que o gato a persegue nem a movimentação das imagens nas pinturas que estão nas paredes. Ao perceber que o gato a perseguia, quando pula sobre ela, o susto é tão grande que a menina desmaia (Figura 6). No desenrolar das ações, as ideias da oposição semântica, portanto, alternam de uma qualificação eufórica com valor positivo para a atenção, e uma qualificação disfórica com valor negativo à distração, para o contrário. 
Figura 6 - O desmaio da menina, o susto das obras

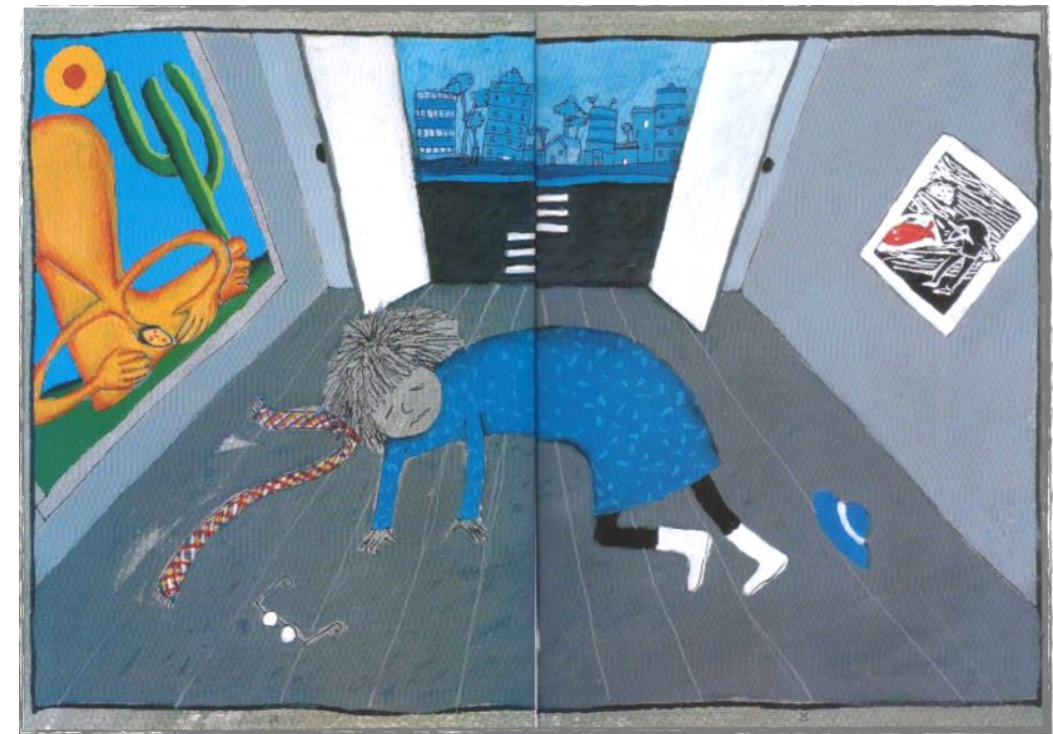

Fonte: CASTANHA, 2008, p.25-26

Para a menina a /distração/ predomina como valor positivo, caracterizando o seu modo de agir e ser ao longo da história. A /atenção/ apenas define o seu modo de agir em três momentos distintos: quando encara o leitor, antes de iniciar o seu passeio pela galeria; quando se coloca diante do quadro/gato (Figura 4); e, no final, quando admira a obra de arte feita pelo gato, retratando os dois juntos (Figura 7). $\mathrm{O}$ gato, ao contrário, relaciona-se do início ao fim da narrativa com a /atenção/, voltando seu olhar para a menina e perseguindo-a pelos corredores da galeria, sendo, portanto, o actante central da narrativa.

Figura 7 - Admiração frente à obra de arte pintada pelo gato

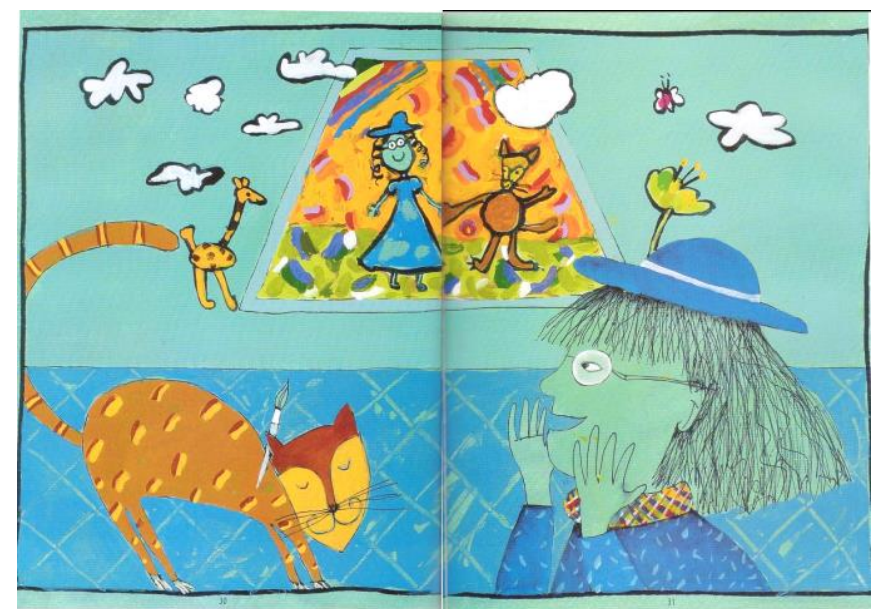

Fonte: CASTANHA, 2008, p. 30-31 
A /atenção/, semanticamente qualificada como eufórica com valor positivo, é o que se busca no desenrolar da história. A passagem da distração à atenção ocorre a partir da ação do gato, o pulo do gato literalmente sobre a menina, é que a leva do desmaio assustado à atenção, ao se deparar com o desenho feito por ele. Percebemos essa transformação a partir da figura da menina, que se apresenta com pouca preocupação com a proporcionalidade ou a representação fiel de um ser humano. Estabelece, assim, ancoragem com a realidade e, ao mesmo tempo, aproxima-se do enunciatário que está implícito nessa obra, o leitor infantil.

Da mesma maneira, o espaço apresentado estabelece relação com a realidade e, o virar de páginas que acompanha o passeio da menina, determina a passagem do tempo. O discurso plástico compõe-se ao longo das páginas, mostrando ao leitor uma narrativa cujo tempo organiza-se a partir do desenrolar das ações que se relacionam com o lugar onde tudo acontece. Por meio desses elementos, instaura-se o tema central dessa história contada por imagens: a interação com objetos artísticos que resultam em produção sensível de sentido. A figurativização do espaço de exposição, bem como a reprodução das obras (esculturas e pinturas) de artistas brasileiros conferem coerência ao texto.

A organização espacial estabelece o conteúdo desse texto e, é reforçada no plano da expressão que, por meio de elementos plásticos, configura o texto imagético que se apresenta. Essa constituição é percebida, primeiramente, na dimensão topológica, o modo com que os atores, os espaços são mostrados a cada página. $\mathrm{O}$ ponto de vista cinematográfico adotado pela autora enfatiza a oposição semântica fundamental. Com pontos de vista mais próximos (close) ou amplos (panorâmicos), as ideias opostas de /atenção/ vs. /distração/ podem ser identificadas. A apresentação da cena em close chama a atenção do leitor para um aspecto específico, determina o que olhar. Já a visão panorâmica do espaço dispersa o foco, distrai a atenção do leitor.

As formas que se constituem por traços e representações fantasiosas ou mais realistas corroboram, coerentemente, para que a oposição fundamental seja ressaltada. A mesma coerência é alcançada a partir da configuração cromática. A cada página, o uso de uma cor vibrante que, ao mesmo tempo, emoldura a cena e preenche o seu plano de fundo. Observa-se uma variação que a princípio parece 
confusa e sem sentido, já que algumas cores se repetem de maneira desordenada e notam-se variações de tonalidade de uma mesma cor.

No entanto, a variedade cromática, em primeiro lugar, relaciona-se com as diferentes cores que compõem as obras (pinturas, esculturas, instalações) expostas na galeria; em segundo lugar, o modo uniforme com que essas cores surgem, colorindo o ambiente da galeria, conferem destaque aos atores e à própria ação narrativa figurativizada.

A leitura dessa obra, portanto, não se limita ao conteúdo, que pode ser sintetizado como uma visita a uma exposição de obras de renomados artistas brasileiros, nem ao seu modo de expressão, envolvendo o traçado do desenho infantil em comparação com obras já reconhecidas no cânone das artes visuais. Ler a obra Pula, gato! é uma aventura que envolve mergulhar no entrelaçamento do texto, de sua expressão e de seu conteúdo, na tentativa de entender os seus mistérios e, de repente, alcançar o pulo do gato, identificando e produzindo sentidos possíveis na engenhosidade do texto.

Nesse texto, a narrativa apresentada pela obra por meio de imagens é tomada para discutir modos de interação com a arte, modos de ser e agir, um fazer mediador que amplie a compreensão da arte e de seus objetos.

\section{A mediação em artes ou o pulo do gato: instigar o olhar atento}

Segundo o Dicionário Aulete (s/d, online), a expressão pulo do gato pode ser entendida das seguintes maneiras: "informação importante que o mestre não revela e que o discípulo terá de descobrir por si só, elemento fundamental na solução de um problema, recurso engenhoso para sair de uma situação difícil”. Na língua inglesa, a expressão ace in the hole corresponde ao pulo do gato em língua portuguesa. É com a figurativização da expressão em língua inglesa que nos deparamos na capa da obra analisada.

No presente texto, o pulo do gato que pretendemos discutir é o ato de mediar, entendendo que esse fazer nada tem de misterioso, mas pode ser definido como engenhoso. A engenhosidade do pulo do gato que possibilita uma melhor compreensão de algo, no caso da mediação é entendida como a maneira de auxiliar 
o olhar a perceber o objeto artístico com maior atenção, e, consequentemente, uma produção de sentido por vezes mais sensível em outras mais inteligível ou, quem sabe, envolvendo essas duas perspectivas.

A menina, personagem da história, mesmo estando cercada por obras de arte (pinturas, esculturas e instalações) de diferentes artistas, caminha pela galeria revelando desatenção ou um modo de ver distante e automático. O encontro com a obra que retrata o gato, porém, altera esse modo de ver. Nesse modo de ser da personagem percebemos duas maneiras de ver que podem ser identificadas na relação que estabelecemos com o mundo e seus objetos sensíveis. Landowski (2004, p.98), ao abordar os modos de presença do que é possível ver no nosso cotidiano, explica que podemos permanecer afastados dos objetos ou nos deixarmos contaminar por eles, estabelecendo "dois regimes de sentido tais que a passagem de uma outro implicaria algo como um salto qualitativo na ordem da inteligibilidade".

Reforça-se, portanto, a noção de que uma imagem colocada diante de nossos olhos é, certamente, vista, porém nem sempre revela algum tipo de compreensão seja mais sensível ou mais inteligível. Esse comportamento do ver, que nem sempre significa olhar com atenção, permite-nos (re)afirmar que a interação com um objeto artístico não se resume a uma visão eficiente. A presença de diferentes imagens no nosso cotidiano bem como sua importância em nossas vidas são ressaltadas em diversas discussões por diferentes autores. Essas discussões, normalmente, também vêm acompanhadas de reflexões sobre como tornar visíveis e lisíveis as imagens que nos cercam (BARBOSA, 2010; ACASO, 2006; OLIVEIRA, 2001; BUORO, 2002), pois ver e colocar-se diante da imagem não é o mesmo que olhar e produzir sentido. $A$ imagem por si mesma não é lisível, ela necessita do olhar do sujeito que a percebe, tomando-a para si a partir do sentido produzido.

A mediação cultural é o caminho que tomamos para possibilitar que o modo de lidar com as imagens ou com a arte, de maneira geral, deixe para trás o caminho do ver natural e tome o percurso do olhar contagiado e produtor de sentido. Entendemos que o fazer mediador pode qualificar a capacidade de ver numa interação que envolve tanto as imagens, com as quais interagimos, quanto os diferentes olhares, voltados para ela com a intenção de atribuir-Ihes sentido. 
Mediar é um fazer, como dito anteriormente, que pode ser caracterizado como engenhoso. Esse fazer interativo envolve um mediador e um ou mais sujeitos da mediação num processo que visa à compreensão a partir de um objeto de sentido. No caso da narrativa analisada anteriormente, o gato colocou-se como mediador e como objeto de sentido. A figura do gato auxiliou a menina a mover-se no percurso entre a distração e a atenção. Foi o gato quem possibilitou que o olhar da menina fosse arrebatado, numa interação que envolveu simultaneamente diferentes regimes de interação para que o sentido fosse estabelecido até alcançar a atenção completa e produtora de sentido. A figurativização disso é encontra na imagem final da narrativa que revela a conjunção completa entre o espaço de exposição, as obras, o gato e a menina (Figura 8).

Figura 8 - A despedida

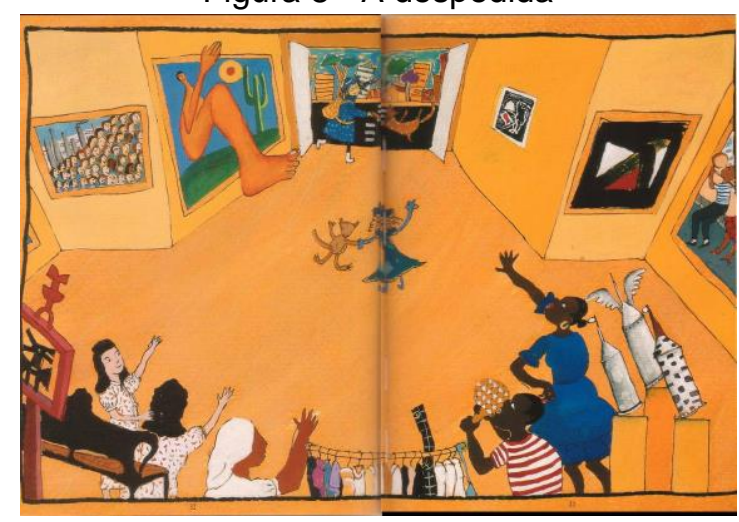

Fonte: CASTANHA, 2008, p. 32-33

Os modos de ser e agir são as principais engenhosidades que podem auxiliar o fazer mediador a estabelecer a conjunção entre mediador, sujeito mediado e objeto de sentido, num determinado contexto. Com base nos trabalhos de Greimas (2002) e Landowski (2009), quatro regimes de interação podem ser definidos: o da programação, o da manipulação, o do ajustamento e o do acidente

Em cada um desses regimes é possível identificar modos de ser e agir diversos do fazer do mediador e do sujeito mediado visando o estabelecimento de uma interação que revele efeitos de sentido. No regime da programação, os papéis são rígidos e o caminho a ser seguido da mesma forma não possui desvios, há um plano traçado, que pode ser representado por perguntas fechadas e respostas óbvias, sem muito espaço para o sujeito mediado expor experiências ou ideias diferentes do que o mediador planejou. A previsibilidade e a circularidade da interação são as 
características essenciais (LANDOWSKI, 2009;2010). A charge apresentada anteriormente (Figura 2) pode ser tomada como exemplo dessa previsibilidade no espaço expositivo. Nela está descrito o comportamento previsível do público, mas também o mediador pode agir com a mesma previsibilidade, pois provavelmente, conhece as obras de arte que irá apresentar ao público e as apresenta através de um discurso automatizado, sem considerar muito os espectadores, apenas o roteiro a ser seguido.

No segundo modo de interação, o regime da manipulação tem o mediador como essencial para desencadear a interação. É o mediador quem busca a reciprocidade do sujeito mediado, valendo-se da sua capacidade de sedução, de provocação. O mediador reconhece o outro como sujeito capaz de construir significações para as imagens. Esse reconhecimento, mesmo sendo baseado em uma relação hierárquica, revela uma perspectiva mais aberta à produção de sentido, pois deixa espaço ao sujeito da mediação para expor seu ponto de vista (o mediador seduz e provoca o olhar do leitor frente à exposição).

No terceiro regime de interação, o regime do ajustamento, o mediador pretende a co-presença com o sujeito mediado. Há maior abertura do que nos outros dois regimes já definidos, pois no plano prático da interação os sujeitos envolvidos não possuem qualquer tipo de hierarquia e os princípios que regulam a interação "emergem pouco a pouco da própria interação, em função do que cada um dos participantes encontra e, mais precisamente [...] em função do que sente [grifo do autor] na maneira de atuar de seu co-participante" (LANDOWSKI, 2009, p. 46, tradução nossa). Nessa maneira de interagir identificamos a alternância de vozes no processo de significação, alcançando uma coerência entre o objeto de sentido e as experiências dos sujeitos que se colocam em contato com a arte. O que se tem é uma relação com comportamentos recíprocos, o que possibilita o contágio entre os sujeitos, dos sujeitos com o objeto artístico e com a prática de produção de sentido em si (NUNES, 2013; 2014).

O quarto regime, o do acidente, é marcado pela imprevisibilidade dos modos de ser e agir, constituindo-se, portanto, numa oposição extrema ao primeiro regime descrito. Na descrição de Fechine e Neto (2010, p.8), o sentido no regime do acidente se constrói baseado no "puro risco", um risco que perpassa os modos de ser e agir 
dos envolvidos. A falta de regularidade de comportamento, causada por diferentes fatores, pode instigar os sujeitos a verem o objeto de sentido de uma maneira diferente daquela a qual estão acostumados. Da mesma maneira, colocar-se inadvertidamente em uma situação baseada numa motivação inadequada ou ainda ignorando as reações do sujeito, pode resultar em um sentido outro daquele esperado caso a interação tivesse ocorrido dentro do regime previsto. O risco pode estar na obra, que desconcerta os sujeitos que com ela se deparam - pensemos na arte contemporânea, com suas instalações que nos provocam. Assim como, o risco pode estar na interação entre os sujeitos que se colocam frente ao objeto de sentido - mediador e mediado , na medida em que possam subverter programas estabelecidos para o diálogo, tendo total liberdade na para expor opiniões, ou ainda revelar essa mesma liberdade na interação física com o espaço, ou com o objeto de arte, movimentando-se, comportando-se fisicamente sem seguir qualquer modelo de comportamento previsível.

O risco pode estar na obra, que desconcerta os sujeitos que com ela se deparam - pensemos na arte contemporânea, com suas instalações que nos provocam. Assim como, o risco pode estar na interação entre os sujeitos que se colocam frente ao objeto de sentido - mediador e mediado -, na medida em que possam subverter programas estabelecidos para o diálogo, tendo total liberdade na para expor opiniões, ou ainda revelar essa mesma liberdade na interação física com o espaço, ou com o objeto de arte, movimentando-se, comportando-se fisicamente sem seguir qualquer modelo de comportamento previsível.

O modo de agir da menina da narrativa, de certa maneira, demonstra essa subversão, pois mesmo estando em um espaço expositivo que espera um olhar de quem vai até ele, ela apenas caminhava pelos corredores, sem se deter em nenhuma obra até encontrar o gato. Se a princípio o acidente estava na falta de conexão da menina com o espaço, por haver a expectativa da programação, a justaposição com um dos quadros por meio da manipulação, levou ao ajustamento e, consequentemente, à programação, no momento em que a menina se detém a olhar um dos quadros.

Assim, a descrição separadamente de cada um dos regimes não significa que não haja sobreposição deles no processo interativo de produção de sentido como 
procuramos explicitar a partir da narrativa do livro de imagem. Além disso, entendemos que esses regimes perpassam o fazer mediador que precisa considerar que os diferentes modos de ser e agir enriquecem a interação e, consequentemente, a produção de sentido (NUNES, 2013).

Um dos possíveis engenhos do fazer mediador, o pulo do gato, é compreender que a produção de sentido se dá a partir da experiência, do vivenciar a arte por meio de diferentes regimes de interação. Em outras palavras, essa experiência é constituída por modos de ser e agir tanto do mediador quando do sujeito mediado, em interação com o objeto olhado, que se sobrepõem, transpõem e complementam, enriquecendo a produção de sentido e a compreensão em relação à arte.

\section{Referências}

ACASO, María. El lenguaje visual. Barcelona: Paidós, 2006.

ACASO, María. La diferencia entre ver y leer. In: Esto no son las torres gemelas: cómo aprender a leer la televisión y otras imágenes. Madrid: Catarata, 2006, p. 89-91.

AULETE, F. J. C.; VALENTE, A. L. dos S. (Eds.). iDicionário Aulete. Rio de Janeiro: Lexikon Editora Digital, s.d. Disponível em: <http://aulete.uol.com.br>. Acesso em 31 de Mai, 2012).

BARBOSA, Ana Mae Tavares Bastos. A imagem no ensino da arte: anos 1980 e novos tempos. 8.ed. São Paulo: Perspectiva, 2010.

BARROS, Diana Luz Pessoa de. Teoria semiótica do texto. São Paulo, Ática, 2005.

BUORO, Anamelia Bueno. Olhos que pintam: a leitura da imagem e o ensino da arte. São Paulo: Educ/Fapesp/Cortez, 2003.

CADEMARTORI, Ligia. Para pensar o livro de imagem. Disponível em: http://grupoautentica.com.br/ download/roteiros/roteiro_livro_de_imagens.pdf. Acesso em: 18 Abr. 2012.

CASTANHA, Marilda. Pula, gato! São Paulo: Scipione, 2008a.

CASTANHA, Marilda. A linguagem visual no livro sem texto. In: OLIVEIRA, leda de. O que é qualidade em ilustração no livro infantil e juvenil: com a palavra o ilustrador. São Paulo: DCL, 2008b, p. 141-161.

FECHINE, Yvana; NETO, João Pereira Vale. Regimes de interação em práticas comunicativas: experiência de intervenção em um espaço popular em Recife (PE). p.1-15. Disponível em: <http://compos.com.puc-rio.br/media/gt4_yvana_fechine_joao_neto.pdf>. Acesso em: 8 Jul. 2010.

LANDOWSKI, Eric. Modos de presença do visível. In: OLIVEIRA, Ana Claudia de (Org.). Semiótica plástica. São Paulo: Hacker Editores, 2004, p. 97-112.

LANDOWSKI, Eric.. Interacciones arriesgadas. Traducción de: Desiderio Blanco. Lima: Universidad de Lima, Fondo Editorial, 2009.

LANDOWSKI, Eric.. Regimes de interação e sentido na educação. Porto Alegre. UFRGS, 2010 (Comunicação Oral). Disponível em: http://www.ufrgs.br/gearte/eventos.html. Acesso em: 30 Jun. 2011.

MARTINS, Mirian Celeste; PICOSQUE, Gisa; GUERRA, Maria Terezinha Telles. Teoria e prática do ensino da arte: a língua do mundo. São Paulo: FTD, 2010.

NUNES, Marília Forgearini. Leitura mediada do livro de imagem no ensino fundamental: letramento visual, interação e sentido. Tese (Doutorado em Educação), (Universidade Federal do Rio Grande do Sul, Porto Alegre, 2013). 
NUNES, Marília Forgearini. Leitura do livro de imagem no contexto escolar: algumas reflexões necessárias. In: GABRIEL, Rosângela; FLÔRES, Onici Claro; CARDOSO, Rosane; PICCININ, Fabiana. Tecendo conexões entre cognição, linguagem e leitura. Curitiba: Multideia, 2014, p.177-187.

OLIVEIRA, Ana Claudia de. Lisibilidade da imagem. Revista da FUNDARTE/ Fundação Municipal de Artes de Montenegro. v.1,n.1. jan/jun 2001, p.5-7.

PRUDHOME, David. La traversée du Louvre. Paris: Futuropolis, 2012.

\section{Marília Forgearini Nunes}

Licenciada em Letras, línguas portuguesa e inglesa e respectivas literaturas (UFSM), Especialista em Língua Inglesa (PUCRS), Especialista em Supervisão Escolar(PUCRS-PUCVirtual), Mestre em Letras (UNISC/PPGL), Doutora em Educação (UFRGS/PPGEDU) com pesquisa financiada pelo CNPq. Pesquisadora do Grupo de Pesquisa em Educação e Arte (GEARTE/UFRGS). Revisora da Revista Gearte. Parecerista do Programa Nacional Biblioteca da Escola (PNBE). Atuou em escolas de educação básica particulares e pública e no ensino superior, na UNIJUí (2008-2009) e na UFSM (20122014). Pesquisa: literatura infantil, mediação da leitura, letramento literário e visual, leitura da imagem a partir da semiótica discursiva, PNBE.

E-mail:mariliaforginunes@gmail.com

Currículo: http://lattes.cnpq.br/5561310307931640 